https://doi.org/10.7203/Normas.2.4658

\title{
REFLEXIONES SOBRE LA IMPLEMENTACIÓN DE UNA SECUENCIA DIDÁCTICA
}

\author{
WRITING DIFFICULTIES AND DIDACTIC SEQUENCES
}

Eduardo ESPAÑA PALOP

Universidad Católica de Valencia, «San Vicente Mártir»

Universitat de València (Facultad de Magisterio)

\section{RESUMEN:}

A partir del trabajo con secuencias didácticas, el grupo de investigación GIEL propone proyectos de escritura en todos los niveles educativos. Aquí se presentan las características que rigen la producción de textos argumentativos en Educación Primaria. Asimismo, se presentan los criterios de análisis que el grupo tiene en cuenta para realizar los distintos módulos que componen una secuencia didáctica.

PALABRAS CLAVE: secuencias didácticas, Educación Primaria.

\section{ABSTRACT:}

From the work with didactic sequences, the group of investigation GIEL proposes writing projects in all the educational levels. Here appear the characteristics that govern the production of argumentative texts in Primary education. Also, there appear the criteria of analysis that the group bears in mind to realize the different workshops that compose a didactic sequence.

KEY WORDS: didactic sequences, primary education. 


\section{INTRODUCCIÓN}

¿Cómo abordar las dificultades en el aprendizaje de la escritura? Esta es la pregunta que constituye la base del proyecto de investigación que ha llevado a cabo el grupo de investigación GIEL de la Universitat de València ${ }^{1}$. La tarea investigadora se ha centrado en la enseñanza y el aprendizaje de la exposición y la argumentación en diferentes niveles educativos (Educación Infantil y Primaria, Educación Secundaria y educación universitaria) y en distintas lenguas (español, catalán e inglés); más concretamente, se ha tratado de relacionar las producciones escritas del alumnado con la práctica docente. Precisamente, el interés principal ha radicado en el abordaje de cuatro niveles educativos y tres lenguas distintas, lo cual ha permitido buscar paralelismos y diferencias para poder contrastar tanto lo que sucede en los distintos niveles como en las diferentes lenguas, con una visión plurilingüe, enmarcada dentro de una enseñanza integrada de lenguas (Ruiz Bikandi, 2005).

En esta ocasión presentamos un estudio parcial que forma parte de esta amplia investigación. A lo largo de este artículo vamos a explicar el proceso que ha llevado a la elaboración de una secuencia didáctica que toma como base el género textual de la nota crítica. La secuencia a la que aquí nos referimos se va a desarrollar en catalán y español a lo largo del segundo y tercer ciclo de Educación Primaria $\left(3\right.$ y $\left.5^{\circ}\right)$ en el Colegio Público Jaume el Conqueridor (Catarroja, València). En este colegio se trabaja con un Programa de Inmersión Lingüística: hay gran presencia de niños que hablan español en casa, por lo que la primera lengua en el colegio es el valenciano; el español se introduce progresivamente en el aula.

Este proyecto se enmarca en la orientación que desde hace un tiempo rige una buena parte de la investigación en el campo de la Didáctica de la Lengua: la creación de un dispositivo de enseñanza asociado a proyectos de escritura. La producción científica sobre las técnicas de enseñanza y las herramientas didácticas ha sido intensa en los últimos lustros; entre estos trabajos se encuentran algunos que han permitido la teorización y la caracterización del género textual para la enseñanza (Dolz y Schneuwly, 1996), y también la elaboración y el uso de secuencias didácticas para evaluar los efectos de la enseñanza sobre la capacidad de los aprendices (Dolz, 1995). La construcción y la realización de estas secuencias didácticas han generado la puesta en marcha de un análisis de los efectos de su implementación en el aprendizaje de los alumnos (Dolz, 1995).

Siguiendo esta línea, el objetivo general que se persigue es conseguir la articulación entre los obstáculos que presentan los alumnos a la hora de argumentar por escrito y una intervención didáctica adaptada. Para realizar la intervención didáctica en las aulas, nos basamos en el uso de secuencias didácticas, según la propuesta de Dolz,

\footnotetext{
${ }^{1}$ Este trabajo se enmarca en el proyecto, financiado por el Vicerrectorado de Investigación de la Universitat de València, titulado Dificultats d'escriptura amb textos argumentatius $i$ explicatius $i$ intervenció didáctica. Una aproximació des de tres llengües [código: UV-INV-AE11-42019].
} 
Noverraz y Schneuwly (2001), los cuales conciben la secuencia didáctica como un conjunto de actividades escolares organizadas de manera sistemática en torno a un género textual oral o escrito.

Dolz (1993) explica la estructura de la secuencia de la siguiente manera:

a) En una primera fase, el profesor propone y discute en clase un proyecto de escritura. Los alumnos producen entonces un primer texto que sirve para observar el nivel de conocimientos de los alumnos sobre el género trabajado y sus características principales, lo cual se explica a los alumnos y constituye la base de los contenidos de un conjunto de módulos.

b) En una segunda fase, los alumnos deben realizar una serie de módulos, cada uno de los cuales supone actividades diversas: debates, análisis y observación de textos, ejercicios de producción simplificada, ejercicios sobre expresiones características de un género, etc.

c) En la tercera fase, gracias a lo que se ha aprendido en los módulos de escritura, los alumnos revisan y rescriben los textos primeros o escriben otros. Esto permite que los alumnos tomen conciencia de lo que han aprendido.

d) La construcción y la experimentación de secuencias didácticas han provocado nuevos desarrollos en las situaciones de aprendizaje. Así, han contribuido a una conceptualización del efecto de las herramientas de enseñanza en la transformación de las capacidades linguísticas de los aprendices y al análisis de los objetivos para la enseñanza de las dimensiones del género textual elegido.

\section{CRITERIOS DE ANÁLISIS}

Para la realización de la secuencia didáctica se analizaron una serie de textos argumentativos producidos por los alumnos. Estos textos se escribieron tanto en castellano como en valenciano, pues, como ya hemos mencionado el colegio integra ambos tipos de lenguas. Los textos de los alumnos de $3 .^{\circ}$ se escribieron en valenciano y los textos de $5^{\circ}$ se escribieron en castellano.

A los alumnos de tercero, a partir de un documental audiovisual, L'ultimatum evolutiu, sobre la conservación y el respeto al medio ambiente, se les pidió que escribieran un texto argumentativo a partir de la siguiente consigna: «¿Qué pensáis de los dos tipos de homo (Consumus y Responsabilus)? ¿Cómo actúan ante la misma situación? ¿Cuál piensas que es la correcta? ¿Por qué?».

En 5. ${ }^{\circ}$ de Educación Primaria, se partió del visionado de la película Billy Elliot. La consigna que se les proporcionó para que escribieran el texto argumentativo fue: 
«Argumenta las razones por las que Billy Elliot debe perseguir, o no, su sueño de ser bailarín».

Hoy en día disponemos de una categorización de los errores de los aprendices que nos permite organizar el trabajo mediante dispositivos y actividades que tienen como finalidad remediar estas dificultades (Dolz, Gagnon y Toulou, 2008). Para trabajar los distintos géneros de texto con base argumentativa, y de acuerdo con el estado de conocimientos actual, hay que tener presente las coordenadas relacionadas con la argumentación, que son: la adecuación al contexto de comunicación, el uso y la construcción de argumentos y contraargumentos, la organización textual y el uso de unidades lingüísticas características de este tipo de textos.

Cada una de estas coordenadas la podemos descomponer a su vez en diversos componentes que debemos tener en cuenta a la hora de producir géneros textuales:

a) La adecuación al contexto argumentativo se caracteriza por siete componentes (Dolz, 1995): el contexto general y los recursos de la argumentación; la intencionalidad; el objetivo del texto; el género textual en el que podemos enmarcar el texto (el entramado social de producción y recepción); las características del emisor; las características del receptor; las diferencias entre el contexto de producción y el contexto de recepción.

b) El uso y la construcción de argumentos y contraargumentos esencialmente conduce a una doble vertiente: la argumentación, a pesar de tener una base monologal, tiene un carácter intrínsecamente dialógico (Camps, 1994), porque está basado en una serie de argumentos que deben anticipar sus posibles contraargumentos para neutralizarlos y poder llegar a ser textos efectivos.

c) La organización textual pone especial atención a sus dos piedras angulares, la cohesión del texto y la coherencia, entendida como el establecimiento de relaciones entre la proposición y el acto ilocutivo (Bernárdez, 1995).

d) Finalmente, el uso de unidades lingüísticas características de estos textos, se centra especialmente en los estructuradores de la información, los conectores, los reformuladores y los operadores argumentativos (Martín Zorraquino y Portolés, 1999).

Tomando estos aspectos como base, se establecieron unos criterios de análisis elaborados por el equipo investigador, a los que se incorporaron algunos otros propuestos por Dolz, Gagnon y Toulou (2008); los mencionados criterios, cuyo objetivo es distinguir los componentes de la escritura, se definen en relación con las operaciones de producción textual. Los errores de escritura se analizan en función de su valor didáctico, como indicadores del grado de dominio que tiene el aprendiz y del que necesita superar. Los aspectos a partir de los cuales se realiza el análisis son la contextualización, la organización y la textualización. 
La contextualización se analiza desde tres grandes bloques:

a) La representación general del texto (pertinencia de las informaciones en relación con la consigna, adaptación a un género textual de referencia); la adaptación a la situación de comunicación; la observación del punto de vista en cuanto a las relaciones intersubjetivas y el posicionamiento de quien habla en relación con las cosas que dice.

b) La polifonía: expresión de diversidad de opiniones y posiciones; aparición de voces diferentes de la de el enunciador, tanto coincidentes como divergentes.

c) Aspectos lingüísticos que manifiestan el posicionamiento del locutor delante del texto.

En la organización también se tienen en cuenta tres grandes vertientes:

a) La planificación: se abordan las partes del texto, la articulación entre las partes y su pertinencia en relación a la planificación convencional de un género.

b) Los contenidos temáticos: el objetivo preciso del texto, la progresión entre las informaciones conocidas y las nuevas.

c) La coherencia del texto.

Finalmente, en cuanto a la textualización, se realiza el análisis a través de cuatro aspectos:

a) Los mecanismos de referencia: sustituciones léxicas que contiene el texto, uso de pronombres, formas verbales, adverbios.

b) El uso de los conectores.

c) El uso adecuado de los signos de puntuación.

d) La revisión de la ortografía.

\section{ANÁLISIS DE RESULTADOS Y SELECCIÓN DE CONTENIDOS}

El análisis de los textos escritos por los alumnos se ha realizado con el propósito de aproximarnos al conocimiento de lo que ellos saben, o no, a la hora de argumentar, previamente a la realización de secuencias didácticas. Estas incidirán en un conjunto de contenidos que serán transversales a los distintos niveles educativos de segundo y tercer ciclo de Educación Primaria, pero que cada secuencia didáctica adaptará para cada nivel de acuerdo con lo que se observe en las producciones previas respectivas. 
Las dificultades detectadas en la producción escrita de los alumnos se organizaron en torno de los tres ámbitos ya mencionados: contextualización, organización y textualización. En cuanto a la contextualización, las principales carencias que se apreciaron fueron que, a pesar de que la mayoría de los alumnos se ciñeron al tema propuesto, no todos argumentaron. Los que argumentaron lo hicieron de manera muy sencilla explicando su propia percepción, sin incluir, salvo excepciones, otros puntos de vista. Los argumentos se limitaron a expresar la opinión personal y se desarrollaron como una sucesión acumulativa, más o menos extensa, de razones. Aparecieron elementos valorativos, pero pocos y sin variedad.

De la adecuación del texto al contexto, lo más destacable es que el destinatario no suele aparecer en el texto.

Si nos centramos en la planificación, hay que resaltar que no se incluye título, por lo que es un aspecto a trabajar, en tanto en cuanto supone operaciones de abstracción y síntesis En general los alumnos argumentan directamente (dan una respuesta a la pregunta planteada) sin que aparezca una tesis o una conclusión.

Por último, en lo relativo a la textualización también se tuvieron en cuenta diversos aspectos. En lo referente a la conexión, hay un uso muy escaso (anecdótico) de los conectores. También escasea el uso de signos de puntuación.

Dentro de la referencia, lo más destacable es la no utilización de elementos de recurrencia léxica: sinónimos, hipónimos, hiperónimos. A veces se producen fallos en la correlación de tiempos verbales.

A partir de este análisis de carencias, se decidió que los contenidos concretos que se trabajarán con los alumnos en los distintos módulos de la secuencia didáctica fueran:

a) En cuanto a la contextualización, se hará especial insistencia en la aparición de información relevante; se trabajará, además, la adaptación del lenguaje según el destinatario y el contexto y la aparición de varios puntos de vista en el texto.

b) Por lo que respecta a la organización textual, se incidirá en la presentación visual del texto escrito, la elaboración de un título y la organización del texto de acuerdo con las estructuras propias de la argumentación. Además, se añade la importancia del uso de argumentos lógicos y coherentes.

c) En relación con la textualización, los aspectos concretos a tener en cuenta son el uso de elementos que muestran valoración en el caso de la argumentación. Igualmente, se trabajará el uso de tiempo verbales adecuados, el uso de conectores, el uso de signos de puntuación y el uso de un léxico específico.

d) Finalmente, aunque la ortografía y los aspectos normativos están incluidos dentro de la textualización, serán considerados como un aspecto transversal que se tendrá en cuenta en los distintos apartados. 
Un hecho que llamó poderosamente la atención, y que en principio no se había planteado dentro de los criterios de análisis fue la presencia de numerosos errores de interlengua en los textos de los alumnos. Como ya se ha mencionado anteriormente, el colegio en el que se desarrolla esta experiencia está situado en Catarroja, una zona en la cual se habla castellano y valenciano. Además, el colegio realiza la escolaridad de los niños íntegramente en valenciano hasta el quinto curso de Educación Primaria. Tanto los textos de tercero (escritos en valenciano), como los textos de quinto (escritos en castellano) poseen errores de léxico, conjugación verbal, ortográficos,... relacionados con la interferencia de lenguas.

Este descubrimiento provocó un cambio de planteamiento en la realización de las secuencias didácticas. En un primer momento, la secuencia de tercero iba a tener el valenciano como lengua vehicular y la de quinto el castellano. Finalmente, se decidió que ambas lenguas apareciesen por igual en las secuencias, ya que así se podría trabajar la transferencia de aprendizaje entre ellas.

\section{COMPOSICIÓN DE LOS MÓDULOS DE APRENDIZAJE}

Para la realización de las secuencias didácticas, se eligió un proyecto que sirvió de elemento conductor de las mismas. Se les pedirá a los alumnos que escriban una nota crítica sobre un libro que habrán leído recientemente. Este proyecto será general para todos los niveles educativos. Como se ha mencionado anteriormente, al inicio de la secuencia didáctica se elaborará un primer texto por parte de los alumnos. Para la elaboración de este primer texto, se les proporciona a los alumnos una consigna.

Una vez escritos estos textos, se plantearán los distintos módulos, a partir de los aspectos concretos a los que ya nos hemos referido. Cada módulo se basa en uno o más de estos aspectos. Los módulos no son independientes entre ellos, es decir, cada nuevo módulo asume los presupuestos trabajados en los anteriores. Pasamos a exponer las actividades concretas que se trabajarán en estos módulos.

En el primer módulo, se comienza con una actividad de reconocimiento y diferenciación de notas críticas frente a otros géneros textuales. Se le presentan diversos textos al alumno (cuentos, recetas de cocina, anuncios,...) y el alumno debe especificar a qué género corresponde cada texto. En el segundo ejercicio, los alumnos deben reflexionar y argumentar por qué han clasificado cada texto dentro de un género concreto. En la siguiente actividad, se deben unir los distintos tipos de géneros que ya han aparecido con sus posibles ámbitos de publicación (periódicos, carteles,...). Finalmente, se plantea que se elijan, entre varias opciones posibles, las finalidades más apropiadas a los géneros textuales presentados. Un ejemplo de las actividades trabajadas en este módulo sería: 
5. Aquí tienes una serie de finalidades que pueden tener los textos. ¿Cuáles corresponden a los textos anteriores? Pon el nombre del texto junto a la finalidad que corresponda. Fíjate que hay más finalidades que textos, por lo que en algunas de ellas no tendrás que poner ningún nombre.

Receta de cocina, folleto publicitario, cuento, noticia deportiva, nota crítica de película

- Explicar cómo se realiza una comida:

- Organizar una evacuación en caso de incendio:

- Informar de un acontecimiento:

- Contar la vida de una persona:

- Anunciar una tienda para que la gente vaya a comprar:

- Dar una opinión sobre una película aportando argumentos:

- Comunicar una queja a alguien:

- Contar una historia:

En el segundo de los módulos, se comienza con una actividad en la que se presentan cuatro textos (dos notas críticas y dos biografías) y cuatro títulos. Los alumnos deben enlazar cada texto con su correspondiente título. Seguidamente se les pide a los niños que identifiquen de los cuatro textos, los dos que son notas críticas y expliquen por qué creen que lo son. La siguiente actividad consiste en que se complete un cuadro en el que se realizan las siguientes preguntas sobre los cuatro textos anteriormente aparecidos: «¿Cuál es el tema del texto? ¿Cuál es la finalidad del texto? ¿El título es adecuado? ¿Qué otro título le pondrías al texto?».

A continuación se presentan dos notas críticas sobre dos famosas películas infantiles (Shrek 4 y Toy Story 3) a las que se les debe poner título. Una vez realizado esto, se organiza a los alumnos por parejas y se les pide que se crucen las siguientes preguntas: «¿Has visto las películas de las que se habla en estos textos? ¿Estás de acuerdo con las opiniones que expresan los textos? ¿Cuál es tu opinión sobre Shrek 4? ¿Cuál es tu opinión sobre Toy Story 3?».

La siguiente actividad consiste en completar una parrilla compuesta por unas preguntas relacionadas con unos deseos que, en teoría, realizan unos niños sobre el funcionamiento del colegio. Las preguntas que aparecen en el cuadro son: «¿Qué propone la persona que escribe el sueño? ¿Qué razón da para justificar su sueño? ¿Qué personas podrían estar en contra de este sueño? ¿Por qué crees que estarían en contra de este sueño? ¿Cuál es tu opinión sobre este sueño?». 
Finalmente, el módulo concluye con un cuestionario que los niños deben realizar a sus padres acerca de la última película que han visto. Algunas de las preguntas que aparecen en este cuestionario son las siguientes: «¿Qué es lo que más les ha gustado? ¿Qué es lo que menos les ha gustado? » Si recomendarían la película...

Como ejemplo de actividades de este módulo, hemos seleccionado la siguiente:

6. Como ya sabes, entre todos estamos soñando cómo nos gustaría que fuese la escuela del futuro. Aquí tienes diversos sueños que han escrito compañeros tuyos:

1. Me gustaría una escuela sin deberes porque son muy aburridos y prefiero pasar mi tiempo libre jugando.

2. Vull una escola on tots els dies ens donen llepolies al menjador perquè no m’agrada ni la verdura ni la fruita.

3. Estaría muy bien que la escuela tuviese cuadros de pintores famosos en los pasillos. Gracias a Van Gogh he descubierto que me encantan los cuadros.

4. Quiero más clases de ingles durante la semana. Me encantan las lenguas extranjeras.

\section{Completa el siguiente cuadro:}

\begin{tabular}{|l|l|l|l|l|}
\hline & $1^{\circ}{ }^{\circ}$ sueño & $2 .^{\circ}$ sueño & $3 .^{\circ}$ sueño & $4^{\circ}$. sueño \\
\hline $\begin{array}{l}\text { ¿Qué propone la } \\
\text { persona que } \\
\text { escribe el sueño? }\end{array}$ & & $\begin{array}{l}\text { Poner cuadros } \\
\text { de pintores } \\
\text { famosos en los } \\
\text { pasillos }\end{array}$ & \\
\hline $\begin{array}{l}\text { ¿Qué razón da } \\
\text { para justificar su } \\
\text { sueño? }\end{array}$ & & & & $\begin{array}{l}\text { Le encantan las } \\
\text { lenguas }\end{array}$ \\
\hline $\begin{array}{l}\text { ¿Qué personas } \\
\text { podrían estar en } \\
\text { contra de este } \\
\text { sueño? }\end{array}$ & Los profesores & & & \\
\hline $\begin{array}{l}\text { ¿Por qué crees } \\
\text { que estarían en } \\
\text { contra de este } \\
\text { sueño? las }\end{array}$ & & $\begin{array}{l}\text { Porque } \\
\text { chucherías no } \\
\text { son comida sana }\end{array}$ & & \\
\hline $\begin{array}{l}\text { ¿Cuál es tu } \\
\text { opinión sobre } \\
\text { este sueño? }\end{array}$ & & & & \\
\hline
\end{tabular}


En el tercer módulo, se les plantea a los alumnos que es el cumpleaños de una niña de otro colegio. Por su cumpleaños sus padres le regalan una serie de dibujos. Ella, como no sabe cuál elegir, ha pedido consejo a sus compañeros de clase. Estos le han recomendado dos series: Phineas y Ferb y Bob Esponja. En la actividad aparecen dos textos (notas críticas) sobre estas series.

El alumno debe rellenar unas fichas sobre estos textos en las que se le realizan las siguientes preguntas: «¿Qué serie está recomendando? ¿Qué información da sobre el argumento de la serie? ¿Qué argumentos da para defender que le gusta la serie? ¿Cuál es tu opinión sobre esa serie?».

Una vez completadas estas fichas, se le pide al alumno que realiza una ficha similar sobre una serie diferente que quiera recomendar a la niña. Un ejemplo de estas actividades sería:

1. Es el cumpleaños de Marina, una niña de Manises. Sus padres le quieren regalar unos dvds de dibujos animados. Le han dejado elegir entre dos: Bob Esponja y Phineas y Ferb. El problema es que ella no sabe cuál elegir. Para poder decidirse, les ha pedido consejo a sus compañeros de clase. Aquí tienes dos consejos que le han dado. Lee cada consejo y completa la ficha que hay después.

A.

En mi opinión, Bob Esponja es la mejor elección. Bob siempre se está metiendo en líos, aunque él lo único que quiere es estar tranquilo en su trabajo y disfrutar de su vida en el mar. En sus aventuras siempre le acompañan sus amigos Patricio y Arenita, y su mascota Gary. Además, su vecino Calamardo Tentáculos siempre está enfadado con él.

Creo que con Bob Esponja no te vas a aburrir nunca, porque cada capítulo tiene una aventura diferente y todas son muy extrañas y entretenidas a la vez. Además, todos los personajes de la serie son muy divertidos.

\section{Pensad las respuestas en pareja y completad la ficha.}

¿Qué serie está recomendando?

¿Qué información da sobre el argumento de la serie?

1.

2.

3. 
4

¿Qué argumentos da para defender que le gusta la serie?

1.

2

3.

4

¿Cuál es tu opinión sobre esta serie?

El cuarto módulo trabaja los aspectos de textualización de la nota crítica y presta atención al léxico que se debe emplear, a los marcadores del discurso y a la acentuación.

La primera de las actividades consiste en completar diversas notas críticas sobre obras escultóricas con diversos marcadores discursivos.

En los dos ejercicios siguientes, se les proporciona a los alumnos diversas palabras que expresan opiniones, gustos, preferencias, etc. Estas palabras se deben clasificar dependiendo de si son verbos o no, y dependiendo de si introducen valoraciones positivas o no. Seguidamente, aparecen una serie de ejercicios en los que, a partir de las palabras que aparecen en dos notas críticas, se trabajan diversas cuestiones relacionadas con la acentuación (separación en sílabas, reconocimiento de la sílaba tónica, clasificación de las palabras en agudas, llanas y esdrújulas,...). Como ejemplo de actividad:

4. Observa la siguiente lista de palabras. Divídelas en dos columnas según sean palabras que sirvan para introducir una opinión o según sean palabras que expresen un sentimiento concreto.

Creo, me agrada, me disgusta, opino, agradable, divertido, me hastía, me repele, gracioso, me fascina, pienso, me parece, entretenido, aburrido, considero, en mi opinión, me encanta, pesado, para mí, desde mi punto de vista, bueno, magnífico, tedioso, monótono, me gusta, me desagrada. 


\begin{tabular}{|l|l|}
\hline $\begin{array}{l}\text { Palabras que sirven para introducir una } \\
\text { opinión }\end{array}$ & $\begin{array}{l}\text { Palabras que expresan concretamente los } \\
\text { gustos, sentimientos, opiniones... }\end{array}$ \\
\hline Creo, opino & me agrada, me disgusta, \\
\hline
\end{tabular}

Dentro de este último módulo, nos gustaría también mostrar un ejercicio en el que se intenta trabajar la transferencia lingüística entre el castellano y el valenciano. En este caso, se trata de dos actividades en las que los alumnos deben usar los marcadores del discurso (pero unos en castellano y otros en valenciano) en dos textos diferentes. Tanto los marcadores en castellano como en valenciano son ordenadores de la información. El marcador que marca el inicio del texto y el marcador que marca la parte final es el mismo. Cambian los marcadores intermedios.

Se trata de que los alumnos sepan que hay diversidad de opciones tanto en castellano como en valenciano:

2. Aquí tienes la nota crítica que ha escrito un profesor. Complétala con estas palabras:

en primer lugar, en segundo lugar, en tercer lugar, finalmente

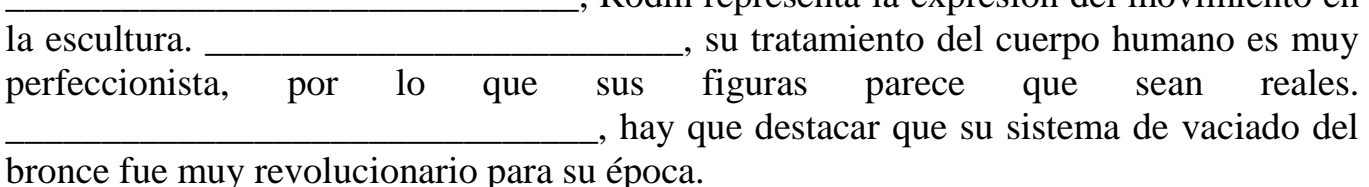

Me encantan las esculturas de Rodin. Disfruto muchísimo cada vez que veo una de ellas. Creo que transmiten una belleza y una humanidad increíbles. Su uso de las formas hace que las esculturas parezcan reales y eso hace que sean maravillosas. Pienso que sus esculturas son a la vez bonitas y misteriosas, siempre dan un poco de miedo creo que Auguste Rodin sería una opción

magnífica para una semana cultural el curso que viene. 
3. Esta nota crítica és d'un altre professor. Completa-la amb les paraules següents:

en primer lloc, per un costat, per un altre costat, per a finalitzar.

cal dir que Rodin, reconegut impresionista, és considerat un dels escultors més importants del segle XIX. Les seues figures són realistes i reflectixen l'espiritualitat de les persones.

\begin{tabular}{llll} 
& & & \\
tenen unes formes $\tan$ & $\begin{array}{c}\text { crec que les escultures de Rodin són molt boniques i } \\
\text { definides que pareixen persones reals. }\end{array}$ \\
\hline
\end{tabular}
interior de les persones i transmeten els seus sentiments.

considere que el bronze és un element molt millor per a les escultures que el marbre.

Una vez llevados a cabo todos los módulos, se pedirá a los alumnos que vuelven a escribir el texto inicial. Como actividad final, se proporcionará los textos escritos al principio de la secuencia didáctica y se pedirá que los analicen y extraigan sus carencias. Una vez sean conscientes de que los textos que escribieron al principio se pueden mejorar, se les pedirá que los reescriban. Con esto se pretende que ellos mismos puedan comprobar y poner en práctica sus aprendizajes.

Durante cada uno de los módulos, se han incluido pequeños recordatorios teóricos para que el alumno sea consciente de lo que está aprendiendo. Estos apuntes no pretenden sistematizar de forma exhaustiva todo aquello que se está trabajando. Son, más bien, puntos de reflexión que deben servir al profesor para verbalizar y sistematizar el aprendizaje que se está llevando a cabo. Mostramos aquí el último de ellos que incluye la mayoría de los puntos que aparecen a lo largo de los distintos módulos:

\section{Recuerda:}

- El título es una parte importante del texto.

- La nota crítica debe contener una explicación sobre las características técnicas de la obra artística.

- Tu opinión debe estar basada en razones.

- Debes organizar la información del texto mediante marcadores.

- Recuerda que todas las palabras tienen una sílaba más fuerte. Algunas palabras llevan tilde.

- Existen palabras que sirven para empezar a expresar tus pensamientos, como creo, opino. 


\section{CONCLUSIONES}

Con esta aportación, pretendemos, en primer lugar, dar a conocer el trabajo con secuencias didácticas dentro del aula. Este tipo de trabajo aporta diversas ventajas, entre las cuales nos parecen de especial importancia dos de ellas: por un lado, el hecho trabajar la escritura a partir de géneros concretos y de forma contextualizada; por otro lado, la necesidad de partir de las necesidades reales de los alumnos para la realización de las actividades.

También hemos pretendido exponer brevemente el estado en que se encuentra nuestra investigación hasta el momento; hemos realizado el análisis de una serie de textos escritos por alumnos de tercero y quinto de Educación Primaria; esta tarea ha tenido como objetivo la detección de los obstáculos que encuentran los alumnos a la hora de argumentar por escrito para, en última instancia, articular una intervención didáctica adaptada. La detección de errores de interlengua (valenciano-castellano), a su vez, nos ha conducido a la elaboración de las secuencias didácticas con actividades en ambas lenguas, con el objetivo de trabajar la transferencia de aprendizaje entre ellas.

La mencionada intervención se ha concretado en el diseño de secuencias didácticas adecuadas a las capacidades de los alumnos. El siguiente paso será su implementación al aula, lo cual nos permitirá estudiar los progresos obtenidos con la realización de la secuencia didáctica en la escritura de estos textos, e igualmente investigar sobre el desarrollo de secuencias didácticas en las aulas, los medios utilizados, la evaluación de las producciones iniciales/finales, la progresión de la secuencia y, finalmente, la atención de los alumnos con dificultades.

\section{REFERENCIAS BIBLIOGRÁFICAS}

AlEZA IZQUIERDO, Milagros, coord. ${ }^{\mathrm{a}}$ (2010): Normas y usos correctos en el español actual, Valencia, Tirant lo Blanch.

BERnÁRDEZ, Enrique (1995): Teoría y Epistemología del Texto, Madrid, Cátedra.

CAMPs, Anna (1994): L'ensenyament de la composició escrita, Barcelona, Barcanova.

CASSANY, Daniel (2000): Construir la escritura, Barcelona, Paidós.

CASSANy, Daniel (2005): Describir el escribir: cómo se aprende a escribir, Barcelona, Paidós, 13. a edición.

CASSANY, Daniel (1993): Reparar la escritura, Barcelona, Paidós. 
CASSANY, Daniel (2002): La cocina de la escritura, Barcelona, Anagrama.

DoLZ, Joaquim (1994): «Seqüències didàctiques i ensenyament de la llengua: més enllà dels projectes de lectura i d'escriptura», Articles, 2, 21-34.

DoLZ, Joaquim (1995): «L'apprentissage des capacités argumentatives: étude des effets d'un enseignement systématique et intensif du discours argumentatif chez des enfants de 11-12 ans», Bulletin Suisse de Linguistique Appliquée, 61, 137-169.

Dolz, Joaquim y Roxane Gagnon y Simon Toulou (2008): Production écrite et difficultés d'apprentissage, Genève, Carnets des sciences de l'éducation.

Dolz, Joaquim y Michèle NoverRaz y Bernard SchNeuwly (2001): Séquences didactiques pour l'oral et pour l'écrit, Bruxelles, Editions de Boeck.

Dolz, Joaquim y Bernard SCHNEUWLY (1996). «Genres et progression en expression écrite: éléments de réflexion à propos d'une expérience romande», Enjeux, 37/38, 49-75.

MARTín Zorraquino, M. ${ }^{a}$ Antonia y José Portolés (1999): «Los marcadores del discurso», en Bosque, Ignacio y Violeta Demonte (dirs.), Gramática descriptiva de la lengua española. Madrid: Espasa Calpe, capítulo 63.

Montolío, Estrella, coord. a (2000): Manual práctico de escritura académica, Barcelona, Ariel, vols I y II.

REYES, Graciela (1998): Cómo escribir bien en español. Manual de redacción. Madrid, Arco Libros.

RUIZ BIKANDI, Uri (2005): «La reflexió interlingüística: ajudar a pensar en/amb/sobre tres llengües», Articles de Didàctica de la Llengua i de la Literatura, 38: 51-66. 
